\title{
NACIONALIDADE NA IMPRENSA E NO RÁDIO: UMA POLIITICA DE LÍNGUAS NA ERA VARGAS
}

\author{
Nationality in the Press and on Radio: Nacionalidad en la imprenta y en radio: \\ A Language Policy in the Vargas Era una política de lenguas en la Era Vargas
}

\author{
Andréa Franciéle Weber* \\ Universidade Federal de Santa Maria (UFSM), \\ Departamento de Ciências da Comunicação, Frederico Westphalen, RS, Brasil
}

\begin{abstract}
Resumo: Este artigo estuda a regulação da nacionalidade no rádio e nos jornais, buscando interpretar seu efeito sobre a política de línguas nesses veículos. Para tanto, ancora-se na Análise de Discurso de linha francesa e na História das Ideias Linguísticas no Brasil. O corpus de análise envolve a legislação para os meios de comunicação promulgada durante a Era Vargas (1930-1945). O trabalho discute como a política para as nacionalidades resultou em uma política para as línguas na imprensa escrita e no rádio, ao favorecer ou limitar o direito à voz de brasileiros natos, brasileiros naturalizados e estrangeiros. Mostra, também, que a regulação do direito à palavra constituiu uma tentativa de controle da produção do discurso, provocando a interdição do estrangeiro nesses veículos.
\end{abstract}

Palavras-chave: História das ideias linguísticas. Análise do Discurso. Política de línguas. Mídia.

\begin{abstract}
This paper studies the nationality regulation on radio and newspapers, trying to understand its effect over the language policy in those communication vehicles. For this purpose, we based the discussion on the Discourse Analysis and the History of Linguistic Ideas in Brazil. The corpus involves the legislation for the mass media published during the Vargas Era (1930-1945). In general, we discuss how the nationality policy resulted in a policy for the languages on radio and the written press, when increased or limited the right to speak for native or naturalized Brazilians and foreigners. Furthermore, the analysis shows that the right to speak regulation was an attempt to control the discourse production causing a foreigner interdiction in those particular vehicles.
\end{abstract}

Keywords: History of Linguistic Ideas. Discourse Analysis. Language policy. Media.

Resumen: Este artículo estudia la reglamentación de la nacionalidad en el radio y en los periódicos, buscando interpretar su efecto sobre la política de lenguas en eses vehículos. Para ello, se ancla en el Análisis del Discurso de línea francesa y en la Historia de las Ideas lingüísticas en Brasil. El corpus de análisis involucra la legislación para los medios de comunicación promulgada durante la Era Vargas (19301945). El trabajo discute cómo la política para las nacionalidades resultó en una política para las lenguas en la imprenta escrita y en el radio, cuando favoreció o limitó el derecho de voz de brasileños natos, brasileños naturalizados y extranjeros. También muestra que la reglamentación del derecho a palabra constituyó una tentativa de control de la producción del discurso, provocando la interdicción del extranjero en eses vehículos.

Palabras clave: Historia de las ideas lingüísticas. Análisis del Discurso. Política de lenguas. Media.

* Doutora em Letras/Estudos Linguísticos. Professora Adjunta do Departamento de Ciências da Comunicação da Universidade Federal de Santa Maria (UFSM) campus Frederico Westphalen. ORCID: https://orcid.org/0000-0001-5948-6293.E-mail: andrea.weber@ufsm.br. 
Estrangeiros. Brasileiros natos. Brasileiros naturalizados. Essas categorias de nacionalidade foram largamente utilizadas na regulação do acesso à palavra na imprensa escrita e no rádio, na Era Vargas (1930-1945). Elas organizavam o direito à posse, à direção e à redação nesses veículos de comunicação e se dispersaram pelas constituições, decretos, decretos-leis e regulamentos do setor instaurados nesse período. Entender como a legislação estabeleceu a relação entre nacionalidade e direito à palavra nesses veículos é um dos objetivos deste artigo. Outro objetivo é interpretar o efeito dessa relação sobre a distribuição política das línguas na imprensa escrita e no rádio. Trata-se de uma breve reflexão, cujo horizonte é a ainda pouco discutida política de línguas para os meios de comunicação daquela época.

Para desenvolver essa questão, tomamos como referência histórica o nacionalismo que caracterizou a Era Vargas, seu ideal de unidade e soberania da nação, sustentado por uma trajetória governamental de crescente autoritarismo e populismo. Estudar a relação entre nacionalidade, língua e direito à palavra na imprensa escrita e no rádio daquela época contribui para repensar esse período marcante da história brasileira, mas também para compreender um pouco do presente do país. Isso porque alguns itens da regulação jurídica daquela época permaneceram no tempo ou inspiraram legislações posteriores para os meios de comunicação nacionais. Além disso, mesmo nos casos em que a legislação foi revogada ou a fiscalização afrouxada, os efeitos desse jogo de fala e silêncio permanecem na memória dos brasileiros, uma vez que a memória não constitui aprendizagem, mas filiação histórica, como diz Pêcheux (1990).

Quando mencionamos direito à palavra ou à voz na imprensa e no rádio, estamos pensando no acesso à cadeia de produção de textos ${ }^{1}$ que caracteriza a imprensa escrita e o rádio, na qual ocorre um trabalho colaborativo e hierárquico, em que diversos profissionais, em variadas funções e cargos, orientam, leem, ajudam, editam, limitam, julgam uns aos outros. $\mathrm{O}$ fato de haver um texto assinado não significa que há uma autoria única e livre de coerções e contribuições do sistema produtivo do veículo.

No entanto, a legislação historicamente procurou um "autor" a quem responsabilizar. Por isso, desde a primeira regulação da liberdade de imprensa no Brasil, em 1823, o anonimato vem sendo combatido por meio de exigências, como a identificação dos responsáveis pela publicação em seu cabeçalho ou o registro dos profissionais contratados junto aos órgãos estatais competentes. As sucessivas normas presentes na legislação brasileira determinavam ainda que, diante da impossibilidade de identificação do autor empírico de um texto, outro integrante da cadeia produtiva (diretor, impressor, gerente etc.) seria considerado autor para fins de responsabilização (MAGALHÃES, 2011).

Fazemos uma ressalva em relação à autoria, não porque seja nossa intenção aqui discutir esse conceito tão desafiador, mas porque a legislação em estudo buscava a responsabilização criminal do autor por discursos tidos como "abusivos". Essa ideia de responsabilização do autor vai ao encontro de reflexões de Foucault (2001), para quem a função-autor é característica do modo de existência, de circulação e de funcionamento de

\footnotetext{
${ }^{1} \mathrm{O}$ texto, neste artigo, envolve a produção verbal, escrita e oral, bem como imagética e sonora.
} 
alguns discursos no interior da sociedade e passou a ser identificada na medida em que o autor se tornou punível por seus discursos transgressores e recompensado com os direitos de reprodução de sua obra.

Assim, ao limitar a certas nacionalidades o direito à palavra na imprensa escrita $\mathrm{e}$ no rádio, evitava-se (supostamente) os discursos abusivos que ela (supostamente) faria. Além disso, o próprio ato de negar ou permitir a palavra a estrangeiros e nacionais já estabelecia, com a autoridade da lei, aquelas nacionalidades que tinham ou não valor e legitimidade para falar. Por fim, ao determinar quais nacionalidades podiam ter "voz" nesses veículos, legislação da Era Vargas operava, em nosso entendimento, não só uma política para as nacionalidades, mas também uma política para as línguas na imprensa escrita e no rádio.

Segundo Arendt (2002), a "política baseia-se no fato da pluralidade dos homens", funciona em um espaço de relação entre eles, na tentativa de organizar e regular o convívio de diferentes, não de iguais; esse espaço público, ao mesmo tempo, os reúne e os separa uns dos outros. Nessa direção, está a concepção de política de Rancière (1996, p. 373), para quem antes "de ser um conflito de classes ou de partidos, a política é um conflito sobre a configuração do mundo sensível na qual podem aparecer atores e objetos desses conflitos". Logo, a política é o lugar do dissenso e não do consenso entre os homens, pois a racionalidade da política é a de um mundo comum instituído, tornado comum pela própria divisão, diz o autor.

Quando pensamos em língua e política, então, nos referimos àquela inscrição das línguas em um universo de poder na história, nas disputas em que elas estiveram envolvidas, desde a torre de babel e a busca de uma língua universal, até as línguas que sustentam ideologias (GADET; PÊCHEUX, 2004). Compreendemos que a legislação em estudo, ao operar uma política para as nacionalidades, projetava, também, uma política para as línguas, uma vez que muitas nações modernas buscaram construir-se sob o monolinguismo e que este foi o caso do Brasil. Ou seja, mesmo que essa legislação não buscasse regular diretamente a língua a ser usada pelos meios de comunicação, ela contribuiu para uma política de línguas, cujo conceito envolve também usos linguísticos e saberes sobre as línguas em uma dada sociedade (ORLANDI, 2002).

Diante disso, nos perguntamos: que categorias de nacionalidade a legislação para a imprensa e o rádio da Era Vargas silenciava e legitimava? Quais funções exerciam os estrangeiros, brasileiros natos e naturalizados na distribuição da palavra na rotina produtiva de jornais, revistas e emissoras de rádio? De que maneira nacionalidades e línguas se associavam? Que sentidos a legislação produzia para as nacionalidades e para as línguas?

Tomando a legislação do período como arquivo, isto é, como um campo de documentos pertinentes e disponíveis sobre o assunto (PÊCHEUX, 1997), efetuamos um recorte, a fim de proceder à análise. Esse recorte contempla três determinações legais para a imprensa escrita e o rádio, promulgadas entre 1934 e 1942. São elas:

- Constituição de 1934, a primeira da Era Vargas (BRASIL, 1934);

- Decreto 364 de 1935, que concede permissão à Rádio Rio Preto S.A. para estabelecer uma estação radiodifusora (BRASIL, 1935);

- Decreto-lei 910, de 1938, que dispõe sobre a duração e condições de trabalho em empresas jornalísticas (BRASIL, 1938). 
Entendendo, de acordo com Pêcheux (1997), que a materialidade do texto de arquivo não deve ser tomada como linguisticamente transparente, mas sim em sua discursividade, como inscrição de efeitos materiais na história, efetuamos sua leitura buscando os sentidos inscritos na relação entre direito à palavra, nacionalidade e língua. Em seguida, recortamos excertos dessa materialidade discursiva que tratam da nacionalidade dos proprietários, diretores, jornalistas, locutores, revisores, fotógrafos, operadores de áudio e de outras funções técnicas e administrativas desses veículos. Esses excertos passaram a constituir nosso corpus e a ser tratados como Sequências Discursivas (SDs) numeradas como SD1, SD2 e SD3, por sua ordem de mobilização na análise. Lançamos o olhar sobre essas SDs a partir da Análise de Discurso de linha francesa e da História das Ideias Linguísticas.

Os resultados da análise foram organizados em dois tópicos. O primeiro estuda a relação entre nacionalidade e direito à palavra presente na legislação para a imprensa escrita e o rádio, promulgada durante a Era Vargas, e foi intitulado Nacionalidade e direito à palavra na legislação para os jornais e o rádio na Era Vargas. O segundo discute os efeitos dessa relação sobre a política de línguas desses veículos de comunicação e se denomina Nacionalidade e direito à palavra: uma política de línguas?. Por fim, nas Considerações finais, retomamos e contextualizamos parte dos resultados da análise e acolhemos questionamentos sobre a política de línguas para a mídia no Brasil.

\section{NACIONALIDADE E DIREITO À PALAVRA NA LEGISLAÇÃO PARA OS JORNAIS E O RÁDIO NA ERA VARGAS}

Neste tópico, estudaremos o modo como as nacionalidades são reguladas para o exercício da palavra na imprensa escrita e no rádio, na legislação promulgada durante a Era Vargas. A seguir, apresentamos as SDs selecionadas para a análise.

SD1 É vedada a propriedade de empresas jornalísticas, políticas ou noticiosas a sociedades anônimas por ações ao portador e a estrangeiros [...]. A responsabilidade principal e de orientação intelectual ou administrativa da imprensa política ou noticiosa só por brasileiros natos pode ser exercida (BRASIL, 1934, grifo nosso).

SD2 A concessionária é obrigada a:

a) constituir sua diretoria com dois terços (2/3), no mínimo, de brasileiros natos, atribuindo a estes funções efetivas de administração;

b) admitir, exclusivamente, operadores e speakers brasileiros natos, e bem assim a empregar, efetivamente, nos outros serviços técnicos e administrativos, dois terços (2/3), no mínimo, de pessoal brasileiro (BRASIL, 1935, grifo nosso).

\section{SD3 DO EXERCÍCIO DA PROFISSÃO JORNALÍSTICA}

Art. 12. Somente poderão ser admitidos ao serviço das empresas jornalísticas como jornalistas, locutores, revisores e fotógrafos os que exibirem prova de sua inscrição no Registo da Profissão Jornalística, a cargo do Serviço de Identificação Profissional do Departamento Nacional do Trabalho, no Distrito Federal, e das Inspetorias Regionais do Ministério do Trabalho, Indústria e Comércio, nos Estados e Território do Acre.

Art. 13. Para o registro de que trata o artigo anterior, deve o requerente exibir os seguintes documentos:

a) prova de nacionalidade brasileira; (BRASIL, 1938, grifo nosso). 
Primeiramente, vamos lançar o olhar sobre as categorias de nacionalidade que as SDs colocam em jogo: 1) estrangeiros, 2) brasileiros natos e 3) brasileiros.

Em termos de nacionalidade, as categorias estrangeiros e brasileiros natos têm sentidos estreitos: estrangeiro é aquele que se vincula a outra nação; brasileiro nato é aquele que se vincula ao Brasil porque nesse país nasceu. No entanto, a categoria brasileiros é mais ampla e pode ser preenchida tanto por brasileiros natos quanto por estrangeiros que adotaram a nacionalidade brasileira, os brasileiros naturalizados. Assim, os brasileiros naturalizados estão significados nesse discurso por sua ausência na materialidade discursiva, de modo que sua presença se dá no nível do interdiscurso, da memória da língua (ORLANDI, 2007a).

Os estrangeiros aparecem apenas na SD1, envoltos em sentidos de proibição inscritos na expressão "é vedada". Não se estabelece o que o estrangeiro pode, mas, sim, o que ele não pode. $\mathrm{O}$ direito à palavra do estrangeiro na imprensa e no rádio está marcada, desse modo, pela negação, pela exclusão.

No outro polo semântico, os brasileiros natos estão presentes em todas as SDs, seja através da expressão "brasileiros natos" propriamente, seja implícitos na categoria brasileiros ("pessoal brasileiro", "nacionalidade brasileira"). Os brasileiros natos estão unidos a significados de exclusividade, marcados nos advérbios "só", "somente" e "exclusivamente". Também estão inscritos em um universo simbólico de garantias assinalado em "no mínimo". Assim, essa rede de significação constrói a exclusividade ou a garantia de uma proporção mínima de brasileiros natos para o exercício da palavra na imprensa escrita e no rádio.

Em meio a esses dois extremos estão os brasileiros naturalizados, cujo primeiro sentido é a ausência na textualidade. Nessas SDs, eles não estão escritos, não são lembrados na sua especificidade, isto é, como estrangeiros-naturalizados-brasileiros. Eles são significados por sua inclusão implícita na categoria ampla de brasileiros, que, ao materializar-se sob essa palavra, oculta a condição flutuante que caracteriza os naturalizados: são estrangeiros (porque lá nasceram e de lá guardam o fenótipo, a cultura, a língua) e são brasileiros (porque aqui vivem). Ainda assim, os brasileiros naturalizados são parcialmente acolhidos, na rede de significação das garantias e das exclusividades em relação ao acesso à palavra na imprensa e no rádio, por meio da relação com "somente" e "no mínimo".

É possível perceber, nessa rede de sentidos, a política para as nacionalidades: uma tentativa de organizar e regular o convívio de diferentes e não de iguais (ARENDT, 2002). Estrangeiros, brasileiros natos e brasileiros naturalizados são diferentes e estão inscritos em uma trama de significados distintos, que vai da exclusão à exclusividade. Essas categorias de nacionalidade estão divididas no discurso, revelando o dissenso próprio à política, nos termos de Rancière (1996). Passamos, agora, a analisar como esse dissenso é registrado na distribuição da palavra entre as diferentes ocupações profissionais presentes nesses veículos de comunicação.

Ao apresentar essas ocupações, a SD1 trata de "propriedade", "responsabilidade principal e de orientação intelectual e administrativa". A SD2 apresenta "diretoria", "operadores e speakers", "outros serviços técnicos e administrativos". A SD3 se refere a “jornalistas, locutores, revisores e fotógrafos". Podemos organizar essas atribuições 
profissionais em quatro esferas produtivas: a esfera da 1) propriedade, da 2) direção, da 3) redação e dos 4) serviços técnicos e administrativos. Por sua relação mais próxima com a produção do texto, neste estudo nos interessam especialmente as três primeiras esferas, de modo que deixaremos de lado a quarta. Apresentamos, a seguir, dois quadros para melhor compreender a relação da propriedade, da direção e da redação com a nacionalidade na imprensa escrita e no rádio. Vejamos os Quadros 1 e 2:

\begin{tabular}{|l|l|l|l|}
\hline Função/Nacionalidade & Estrangeiros & Brasileiros naturalizados & Brasileiros natos \\
\hline Propriedade & Vedado & Em qualquer proporção & Em qualquer proporção \\
\hline $\begin{array}{l}\text { Direção intelectual e } \\
\text { administrativa }\end{array}$ & Vedado & Vedado & Exclusivamente \\
\hline $\begin{array}{l}\text { Redação (locutores } \\
\text { jornalistas, revisores, } \\
\text { fotógrafos). }\end{array}$ & Vedado & Em qualquer proporção & Em qualquer proporção \\
\hline
\end{tabular}

\section{Quadro 1 - Nacionalidades e ocupações na imprensa escrita com base nas SDs 1, 2 e 3}

Fonte: $\mathrm{O}$ autor.

\begin{tabular}{|l|l|l|l|}
\hline Função/Nacionalidade & Estrangeiros & Brasileiros naturalizados & Brasileiros natos \\
\hline Propriedade & - & - & - \\
\hline $\begin{array}{l}\text { Direção intelectual e } \\
\text { administrativa }\end{array}$ & Máximo 1/3 (1935) & Máximo 1/3 (1935) & Mínimo 2/3 (1935) \\
\hline $\begin{array}{l}\text { Redação (locutores e } \\
\text { operadores de áudio) }\end{array}$ & Vedado & Vedado & Exclusivamente \\
\hline
\end{tabular}

Quadro 2 - Nacionalidades e ocupações no rádio com base nas SDs 1, 2 e 3

Fonte: $\mathrm{O}$ autor.

No Quadro 1, referente à imprensa escrita, o direito à palavra está vedado aos estrangeiros em todas as esferas produtivas: eles não podem ser nem donos, nem diretores, nem repórteres, revisores ou fotógrafos dos jornais e revistas. No rádio, a proibição é um pouco mais branda na esfera da direção, apenas, como mostra o Quadro 2. Portanto, os estrangeiros estavam praticamente impossibilitados de ter voz nesses veículos de comunicação nos anos de vigência dessa legislação. Os estrangeiros sofriam, assim, uma política de silenciamento.

De acordo com Orlandi (2007b), a política de silenciamento se divide em a) silêncio constitutivo, apagamento necessário de palavras ao falar; e b) silêncio local, ou censura, aquilo que é proibido dizer em certa conjuntura devido a injunções sociopolíticas. A censura, ainda em consonância com a autora, constitui, então, qualquer processo de silenciamento que limite o sujeito no percurso de sentidos. Desse modo, entendemos que, por não terem direito à palavra na imprensa e no rádio naquele contexto político, os estrangeiros sofriam um silenciamento local, um processo de censura. Nas palavras de Tfouni (2008), havia dizeres recuperáveis pelo sujeito estrangeiro, mas proibidos localmente, censurados.

\footnotetext{
2 Aqui, a inclusão de "locutores", profissionais típicos do rádio, não coaduna com a condição de empresa jornalística que o decreto-lei visa a regular, tampouco com outros decretos contemporâneos a este que visavam a regular as concessões às emissoras de rádio, o que produz discrepâncias internas na legislação.
} 
Seguindo com a interpretação dos Quadros 1 e 2, vemos que os brasileiros naturalizados não gozam dos mesmos direitos à voz que os brasileiros natos, muito embora todos sejam brasileiros. Na imprensa escrita, os estrangeiros que se naturalizaram podem atuar livremente nas esferas da propriedade e da redação, mas estão proibidos de exercer funções de diretoria. Já no rádio, eles podem atuar na esfera da diretoria de maneira limitada (até 1/3) e estão impedidos de exercer funções de redação. A proibição de voz a brasileiros naturalizados é menor que a imposta aos estrangeiros, mas existe em algumas esferas. Simbolicamente, os naturalizados são situados no entremeio, como se a origem estrangeira não se apagasse com a naturalização e seu perigo estivesse sempre latente.

Assim, a regulação do direito à palavra nos jornais e no rádio constitui uma tentativa de controle da produção do discurso e não de controle do discurso já formulado. Essa constatação vai ao encontro das reflexões de Foucault (1999), de que a própria produção do discurso é controlada e selecionada por procedimentos que têm por função conjurar seus "poderes e perigos". Entendemos que a legislação em análise constitui um desses procedimentos, ao estabelecer critérios para o acesso à fala nesses veículos. O controle do discurso já formulado, por sua vez, se dava de outro modo, pela via da censura prévia aos meios de comunicação, prática que vigorou especialmente durante o Estado Novo (1937-1945).

Ainda pensando nos "poderes e perigos" do discurso, conforme formulado por Foucault (1999), percebemos que o estrangeiro era vinculado a esse discurso perigoso, o que justificava a proibição do acesso à palavra a esse grupo. Já os brasileiros natos eram tidos como os representantes autênticos, legítimos, verdadeiros do discurso nacional (e adequado) e, por isso, tinham seu direito à voz promovido no rádio e na imprensa escrita, com liberdade de atuação, com garantias de proporção mínima (2/3) ou com exclusividades.

A questão da exclusividade é provocativa: por que há espaços de fala que só podem ser exercidos por aqueles que nasceram no Brasil enquanto outros espaços podem ser compartilhados com os estrangeiros que se naturalizaram? Que diferenças o discurso produz acerca da relação de brasileiros natos e naturalizados com o direito à palavra?

Em primeiro lugar, há diferenças para o rádio e para a imprensa escrita. Na imprensa escrita, a direção é exclusiva de brasileiros natos; no rádio, a redação (locutores e operadores de áudio). Essas esferas têm em comum o fato de serem o ponto final dos textos dentro da cadeia de produção discursiva antes de serem publicados. Isto é, na imprensa escrita, a última mão pela qual o texto passa antes de ser publicado é a do diretor; no rádio, a última mão é a do locutor/operador de áudio. Assim, na tentativa de controle dos discursos, a legislação designa a decisão final no ciclo da produção da palavra a brasileiros natos, os representantes legítimos do nacional.

Além disso, há uma questão de modalidade linguística (escrita/oral), que parece importar. Locutores e operadores de áudio trabalham com a linguagem sonora, a palavra oralizada, sua volatilidade e rapidez e, consequentemente, sua dificuldade de controle ao passo que jornalistas, fotógrafos e revisores trabalham com a linguagem visual, a palavra escrita, sua durabilidade e lentidão, mais facilmente controláveis. Assim, a lei exige brasileiros natos para a produção da palavra falada, mas permite brasileiros naturalizados para a produção da palavra escrita. 
Com essa reflexão, nos aproximamos da relação entre nacionalidade e língua. Nossa hipótese é de que esse jogo de autorização e proibição do acesso à palavra tratava de controlar não só o que era dito, mas também a língua com que se dizia. Assim, as categorias estrangeiros, brasileiros naturalizados e brasileiros natos guardavam, no discurso da legislação, uma relação imaginária com a(s) língua(s), o que tentaremos esmiuçar no próximo tópico.

\section{NACIONALIDADE E DIREITO À PALAVRA: UMA POLÍTICA DE LÍNGUAS?}

A relação entre língua e nacionalidade não é direta, muito embora, conforme Hobsbawm (2002, p.71), a "mitologia nacionalista" a tome desse modo. Segundo o autor, o nacionalismo pretende que as línguas sejam as bases fundamentais da cultura nacional e as matrizes da mentalidade pátria; por isso, foram usadas junto com a etnia e a religião, como um traço que aglutina e torna perceptível a nação. No caso brasileiro, a "configuração histórica e política do Brasil como nação institucionalizou a língua portuguesa como língua nacional e oficial, tornando-a hegemônica, sobretudo nos grandes centros urbanos e disseminando-a na região rural [...]" (MARIANI, 2009, p.4).

Desse modo, no Brasil, há uma relação historicamente construída entre nação e língua nacional única. Segundo Guimarães (2003), no imaginário brasileiro ocorrem sobreposições entre os conceitos de língua nacional, língua oficial e língua materna, das quais a principal coincidência é a da língua oficial com a língua nacional, e destas com a língua materna. Nesse imaginário, o brasileiro nato teria, necessariamente, a língua nacional como materna, desconsiderando-se a pluralidade de línguas que ajudaram a compor o país.

No outro extremo, por sua vez, está o estrangeiro, a quem se associam as línguas estrangeiras e nunca a nacional. Nesse sentido, até mesmo os estrangeiros de nacionalidade portuguesa podem ser concebidos como falantes de uma língua diferente da língua do Brasil, devido à percepção de ruptura com a língua da metrópole, muito presente nas ideias linguísticas brasileiras, especialmente até meados da década de 1940 (DIAS, 1995; GUIMARÃES, 2000). Por fim, entre a língua nacional e a língua estrangeira, na mistura e na oscilação, está o estrangeiro naturalizado brasileiro.

Ao aproximarmos nacionalidade, língua e direito à palavra, podemos dizer que controlar a nacionalidade dos falantes/escritores é, também, de certo modo, controlar a língua que circula nos jornais e no rádio. Ao negar-se possibilidade de voz ao estrangeiro, silenciam-se outros sentidos que não estão no conteúdo do que é dito, mas na "pesada e temível materialidade" do discurso, conforme expresso por Foucault (1999, p. 9). Em primeiro lugar, silenciam-se as línguas estrangeiras. Em segundo lugar, silenciam-se as marcas das línguas estrangeiras sobre a língua nacional (os acentos, os empréstimos lexicais etc.). Cria-se, assim, a ilusão de unidade nacional e de unidade da língua; a ilusão de soberania nacional e de soberania da língua. A língua nacional se torna única e pura, isto é, torna-se, imaginariamente, uma língua que não sofre nem o convívio nem a influência das línguas estrangeiras. 
A partir dessa reflexão, podemos interpretar a exigência da legislação da Era Vargas de que os locutores das rádios fossem brasileiros natos. Nesse imaginário, por terem nascido no Brasil, tais locutores necessariamente seriam falantes da língua nacional pura; um estrangeiro naturalizado, por sua vez, não atingiria a língua nacional pura, devido às influências fonéticas da língua estrangeira que lhe era materna; e o estrangeiro seria um difusor da língua estrangeira. Certamente, essa ideia não coadunava com a realidade da época, pois, no Brasil, até a década de 1940, assinala o estudo de Willems (1946 apud SEYFERTH, 1999), nas regiões de colonização estrangeira a população urbana já era bilíngue, ao passo que grande parte da população rural desconhecia a língua portuguesa. Ou seja, muitos brasileiros natos eram falantes de línguas estrangeiras ou da língua nacional com marcas estrangeiras. Isto é, ao contrário do que esse imaginário projetava, muitos brasileiros natos não eram representantes da língua nacional pura.

Como vimos, a regulação do direito à palavra na imprensa escrita e no rádio, na Era Vargas, tinha caráter nacionalista ao privilegiar o brasileiro nato e limitar o estrangeiro nas esferas de trabalho com a produção de sentidos. A língua do escritor/falante era um aspecto que subjazia a essa regulação, tendo em vista que a difusão do discurso, por meio da língua nacional pura, fazia significar a unidade e a soberania da nação. No entanto, um aspecto curioso da legislação é que sua própria materialidade linguística contrariava a soberania e a unidade linguística almejada, ao determinar que a "concessionária é obrigada a: b) admitir, exclusivamente, operadores e speakers brasileiros natos [...]" (SD2). Ou seja, ao usar uma palavra inglesa em um texto voltado à defesa do nacional.

Nesse discurso, constatamos a presença de um equívoco, de marcas de resistência que afetam a regularidade da língua e do discurso, "que explodem, de repente, por detrás da frase ou o gesto mais sagrado" (PÊCHEUX, 2015, p. 15). Ao usar a palavra "speakers" produz-se um deslizamento em direção à língua estrangeira e, com ele, traz-se à superfície a dependência brasileira em relação a outras nações, nesse caso marcada na tecnologia radiofônica e na língua de seus criadores. A inscrição de "speakers" faz significar a frágil soberania da língua nacional, que incorporou a si um termo estrangeiro e o imprimiu, até mesmo, no discurso da legislação. Pouco tempo depois, a palavra "speakers" foi sendo gradativamente substituída por "locutores", de origem latina, na terminologia do setor radiofônico, dentro e fora da legislação.

$\mathrm{Na}$ imprensa escrita e no rádio, a sobreposição imaginária entre língua nacional e materna na distribuição do trabalho entre as diversas nacionalidades constituiu uma contradição, em razão da diversidade de línguas presente no Brasil, mesmo entre os brasileiros nascidos no país. O controle do acesso à palavra com base na nacionalidade não eliminou as línguas estrangeiras dos jornais, tanto que, em 1938, o decreto Decretolei 406 incluiu, em suas disposições gerais e transitórias, um artigo que proibia a publicação de livros, revistas ou jornais em língua estrangeiras nas áreas rurais do Brasil. Mais tarde, em 1941, um despacho do Departamento de Imprensa e Propaganda (DIP) pôs fim a todos os jornais e revistas em língua estrangeira do país (NEUMANN, 2004). No caso do rádio, para autorizar a abertura de uma emissora nas áreas de colonização estrangeira do país, mais do que avaliar se os locutores eram brasileiros natos, o DIP observava seu sobrenome, privilegiando os de origem lusitana (MUSTAFÁ, 2009). 
Calcada na sobreposição entre língua materna e nacional, a legislação que regulava o acesso das nacionalidades à palavra na imprensa escrita e no rádio produziu uma política de línguas para esses veículos. Isso porque essas normativas legais inscreveram as línguas em um universo de poder na história, como dizem Gadet e Pêcheux (2004), no qual a língua nacional buscou garantir sua hegemonia frente às línguas estrangeiras. Além disso, a legislação, ao regular o acesso das nacionalidades à palavra na imprensa escrita e no rádio, produziu efeitos sobre os usos das línguas no cotidiano desses veículos, e os usos diferenciados que se fazem das línguas também constituem sua política (ORLANDI, 2002).

A política para as nacionalidades e para as línguas nos jornais e no rádio constituiu mais uma medida nacionalizante da Era Vargas, uma vez que deu voz ao brasileiro nato e à língua nacional, ao passo que calou os estrangeiros e as línguas estrangeiras. Embora seja mais uma entre várias medidas com esse fim adotadas no período, sua importância não deve ser diminuída, pois foi um fator importante para o controle social dos discursos e, consequentemente, para a construção do imaginário de nação pretendido na época.

\section{CONSIDERAÇÕES FINAIS}

Ao longo deste artigo, buscamos entender como a regulação do direito à palavra na imprensa escrita e no rádio constituiu uma política para as nacionalidades e para as línguas na Era Vargas. Na Introdução, nos perguntávamos: que categorias de nacionalidade a legislação para os meios de comunicação da Era Vargas silenciava e autorizava? Quais funções exerciam os estrangeiros, brasileiros natos e naturalizados na distribuição da palavra na rotina produtiva de jornais, revistas e emissoras de rádio? De que maneira nacionalidades e línguas se associavam? Que sentidos a legislação produzia para as nacionalidades e para as línguas?

$\mathrm{Na}$ busca de respostas a essas perguntas, vimos, ao longo do trabalho, que a regulação das vozes nesses veículos conformou uma tentativa de controle da produção do discurso e não do discurso já formulado. Restringia-se a voz do estrangeiro, independentemente do que ele quisesse dizer. Com isso, silenciam-se outros sentidos que não estão no conteúdo do que é dito, mas em outros lugares do discurso, como o próprio sujeito enunciador e os enunciatários que ele projeta. Embora essa interdição afetasse consideravelmente a liberdade de expressão de estrangeiros, sua condição de censura se confundia com uma simples regulação do acesso à propriedade e ao trabalho na imprensa e no rádio.

Vimos, também, no decorrer da análise, que as categorias estrangeiros, brasileiros naturalizados e brasileiros natos são significadas em polos semânticos que vão da exclusão (do estrangeiro) à exclusividade (do nascido no Brasil). O estrangeiro que se naturalizou brasileiro é situado em uma posição intermediária no acesso à palavra, do qual ele pode usufruir com limitações. Também essas categorias são colocadas em uma relação imaginária com a(s) língua(s). Nesse imaginário, ocorria a sobreposição entre língua nacional e materna, que fazia supor que todo brasileiro nato tinha, necessariamente, a língua nacional como materna. 
Cabe lembrar que a realidade plurilíngue do Brasil da época, porém, frustrava essa percepção e acabou levando a outras medidas legais para o controle das línguas estrangeiras na imprensa e no rádio, como o Decreto-lei 406/1938, que proibia publicações em língua estrangeira nas áreas rurais do país, e a averiguação do sobrenome para tentar identificar a origem e a língua do falante no rádio.

Ainda com relação à língua radiofônica, a exigência contida na legislação de que locutores de rádio fossem, exclusivamente, brasileiros natos estava em consonância com uma preocupação em vigor na época: a "qualidade" da língua nacional falada. O Congresso da Língua Nacional Cantada, ocorrido em 1937, exprimia sua inquietação com a diversidade da fala da língua portuguesa no Brasil. E o rádio estava emergindo, nas décadas de 1930 e 1940, como uma importante novidade tecnológica, capaz de levar a palavra falada e todas as suas nuances regionais e sociais a milhares de pessoas, em todo o território nacional.

Este artigo, antes de encerrar uma discussão, desperta a curiosidade sobre temas relacionados à política de línguas nos meios de comunicação do Brasil. Muitas perguntas ainda persistem no que diz respeito tanto ao direito à voz na mídia quanto à sua relação com a língua e as ideias linguísticas no Brasil.

\section{REFERÊNCIAS}

ARENDT, H. O que é política? [editoria, Ursula Ludz]. 3. ed. Rio de Janeiro: Bertrand Brasil, 2002.

BRASIL. Constituição da República dos Estados Unidos do Brasil de 1934. Disponível em: http://www2.camara.leg.br/legin/fed/consti/1930-1939/constituicao-1934-16-julho-1934-365196publicacaooriginal-1-pl.html. Acesso em: 15 abr. 2017.

BRASIL. Decreto 364 de 4 de outubro de 1935. Concede permissão à Radio Rio Preto S.A. para estabelecer uma estação radiodifusora. Disponível em: http://www2.camara.leg.br/legin/fed/decret/19301939/decreto-364-4-outubro-1935-499109-publicacaooriginal-1-pe.html. Acesso em: 13 maio 2017.

BRASIL. Decreto 910 de 30 de novembro de 1938. Dispõe sôbre a duração e condições de trabalho em empresas jornalísticas. Disponível em: http://www2.camara.leg.br/legin/fed/declei/1930-1939/decreto-lei910-30-novembro-1938-349925-publicacaooriginal-1-pe.html. Acesso em: 15 abr. 2017.

BRASIL. Decreto-lei $n^{\circ} 406$ de 4 de maio de 1938. Dispõe sôbre a entrada de estrangeiros no território nacional. Disponível em: http://www2.camara.leg.br/legin/fed/declei/1930-1939/decreto-lei-406-4-maio1938-348724-publicacaooriginal-1-pe.html. Acesso em: 18 maio 2013.

DIAS, L. F. Os sentidos do idioma nacional: as bases enunciativas do nacionalismo linguístico no Brasil. 1995. 161 f. Tese (Doutorado em Linguística) - Instituto de Estudos da Linguagem, Universidade Estadual de Campinas, Campinas, 1995.

FOUCAULT, M. A ordem do discurso. São Paulo: Loyola, 1999.

FOUCAULT, M. O que é um autor? In: FOUCAULT, M. Ditos e escritos v. III: estética - literatura e pintura, música e cinema. Rio de Janeiro: Forense Universitária, 2001.

GADET, F.; PÊCHEUX, M. A língua inatingivel. Campinas: Pontes, 2004.

GUIMARÃES, E. Língua de civilização e língua de cultura: a língua nacional do Brasil. In: BARROS, D. L. P. (Org.) Os discursos do descobrimento. São Paulo: Edusp, 2000.

GUIMARÃES, E. Enunciação e política de línguas no Brasil. Revista Letras, n. 27, p. 47-53, 2003. Disponível em: https://periodicos.ufsm.br/letras/article/view/11897 . Acesso em: 30 out. 2020.

HOBSBAWM, E. Nações e nacionalismo desde 1780: programa, mito, realidade. Rio de Janeiro: Paz e Terra, 2002. 
MAGALHÃES, A.S. Nascimento e morte da lei de imprensa no Brasil: representações discursivas de autoria em jornalismo. Alfa, São Paulo, v. 55, n. 1, p. 177-204, 2011. Disponível em: http://seer.fclar.unesp.br/alfa/article/view/4173/0. Acesso em: 9 nov. 2017.

MARIANI, B. Quanto vale uma língua? O apagamento do político nas relações econômicas e linguísticas. Encontros de vista; v. 2, p. 1-12, jul/dez 2009. Disponível em:

http://www.encontrosdevista.com.br/Artigos/QUANTO VALE UMA LINGUA O APAGAMENTO DO_POLITICO_NAS_RELACOES.PDF. Acesso em: 21 fev. 2011.

MUSTAFÁ, I. Alô, alô Joinville! Está no ar a Rádio Difusora! A radiodifusão em Joinville/SC (19411961). Joinville: Casamarca, 2009.

NEUMANN, R. M. Correio Serrano: órgão dos interesses regionais. In: DREHER, M.; RAMBO, A. B.; TRAMONTINI, M. J. (Org.) Imigração e imprensa. Porto Alegre: EST/São Leopoldo: Instituto Histórico de São Leopoldo, 2004. p. 91-99.

ORLANDI, E. Lingua e conhecimento lingüístico: para uma história das idéias no Brasil. São Paulo: Cortez, 2002.

ORLANDI, E. Análise de discurso: princípios e procedimentos. Campinas: Pontes, 2007a.

ORLANDI, E. As formas do silêncio: o movimento dos sentidos. Campinas: Pontes, $2007 \mathrm{~b}$.

PÊCHEUX, M. O discurso: estrutura ou acontecimento? Campinas: Pontes, 1990.

PÊCHEUX, M. Ler o arquivo hoje. In: ORLANDI, Eni (Org.). Gestos de leitura: da história no discurso. Campinas: Unicamp: 1997. p. 55-64.

PÊCHEUX, M. Ousar pensar e ousar se revoltar: ideologia, marxismo, luta de classes. Décalages, v. 1, n. 4, 2015. Art. 15. Disponível em: https://core.ac.uk/download/pdf/73345743.pdf. Acesso em: 30 out. 2020.

RANCIÈRE, J. O dissenso. In: NOVAES, A. (Org.). A crise da razão. São Paulo: Cia das Letras; Distrito Federal: Ministério da Cultura; Rio de Janeiro: Fundação Nacional da Arte, 1996.

SEYFERTH, G. Os imigrantes e a campanha de nacionalização do Estado Novo. In: PANDOLFI, D. (Org.). Repensando o Estado Novo. Rio de Janeiro: Fundação Getúlio Vargas, 1999. p.199-228.

TFOUNI, F. E. O interdito e o silêncio: duas abordagens do impossível na linguagem. Linguagem em (Dis)curso, Tubarão, v. 8, n. 2, p. 353-371, maio/ago. 2008. Disponível em:

http://www.portaldeperiodicos.unisul.br/index.php/Linguagem_Discurso/article/view/393. Acesso em: 15 out. 2017.

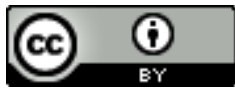

Este texto está licenciado com uma Licença Creative Commons Atribuição 4.0 Internacional. 